\title{
Convergent Syntheses of Dendrimers Having Photo-responsible and Redox-active Unit
}

\author{
Jae Wook Lee, Byung-Ku Kim, and Sung-Ho Jin ${ }^{\dagger}$
}

\author{
Department of Chemistry, Dong-A University, Hadan-2-dong, Busan 604-714, Korea. *E-mail: jlee@dau.ac.kr \\ ${ }^{\dagger}$ Department of Chemistry Education \& Center for Plastic Information System, Pusan National University, Busan 609-735, Korea \\ Received December 15, 2004
}

Key Words : trans-1,2-Bis(4-pyridyl)ethylene, Dendrimers, Dendrons

Dendrimers are well-defined, tree-like macromolecules, with a high degree of order and the possibility to contain selected chemical units in predetermined sites of their structure. Dendrimers are currently attracting the interest of many scientists because of their unusual chemical and physical properties and the wide range of potential applications. It is possible to design and synthesize dendrimers containing a variety of functional groups that can be useful for various field and purposes. ${ }^{1}$ Dendrimers have great potential as such nano-scale molecules.

During the past two decades various dendrimers with different cores, branches, and end groups have been synthesized and applied in different area including drugdelivery, catalysis, light energy harvesting, sensor, etc. ${ }^{2}$ Dendrimers with photo and/or redox-active components have been proposed as promising materials for miniaturized information storage. ${ }^{3-10}$ Therefore syntheses of nano-scale molecules possessing device-like properties are of much interest in modern science and technology. In conjunction with our program directed at the design and syntheses of nano-structured functional materials, we herein present the high yielding and first synthesis of dendrimers which contain a trans-1,2-bis(4-pyridyl)ethylene residue with two

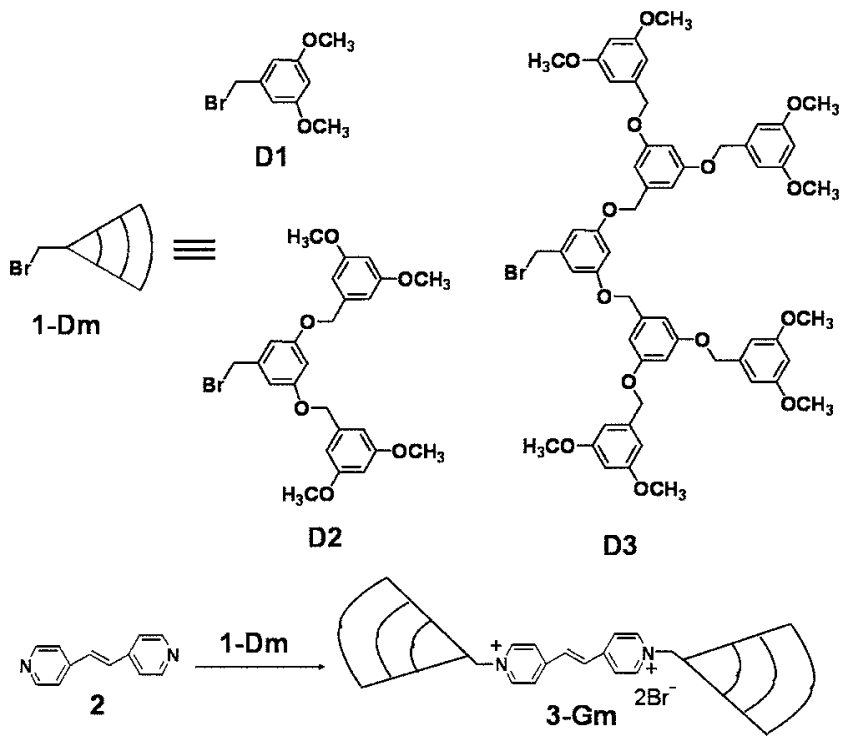

Figure 1. Structures of benzyl bromide dendrons 1-Dm $(\mathrm{m}=1,2$, and 3: generation of dendron) and schematic representation of dendrimers 3-Gm. identical Fréchet-type dendrons (first to third generation).

The synthetic strategy for the preparation of dendrimers utilized a convergent method (Figure 1). ${ }^{2 \mathrm{~d}}$ The most attractive feature of the convergent synthesis is that requires a very small number of transformations per molecule in the coupling step. The reaction can be driven to completion with equivalent or only a slight excess of reagent, providing greater structural control in preparing well-defined unsymmetrical dendrimers. Prior to the synthesis of dendrimers, the benzyl bromide dendrons 1-Dm $(\mathrm{m}=1,2$, and 3: generation of dendron) were prepared according to the reported procedure. ${ }^{11}$ To probe the viability of our approach, the coupling was initially studied using low generation dendron bromide in various solvents such as THF, $\mathrm{CH}_{3} \mathrm{CN}$, DMF, and DMSO. We were pleased to find that the reaction between trans-1,2-bis(4-pyridyl)ethylene 2 and three molar equivalents of dendron bromide 1-D1 in DMSO for $48 \mathrm{~h}$ at room temperature afforded the symmetrical dendrimer 3-G1 in $98 \%$ yield. With this result, we next examined the reaction with higher generation dendron bromides. Reaction between trans-1,2-bis(4-pyridyl)ethylene $\mathbf{2}$ and three molar equivalents of the corresponding dendron bromides 1-Dm in DMSO for $48 \mathrm{~h}$ at room temperature afforded the symmetrical dendrimers 3-Gm with redox active and photoresponsible unit in $95 \%$ and $86 \%$ yields for $\mathbf{G 2}$ and G3, respectively.

The purification of the resulting compounds was achieved by precipitation adding non-polar solvent such as THF, EtOAc, and diethyl ether, because these dendrimers have two positive charges. Eventually we can prepare highly pure dendrimers by a convergent method. The yield of dendrimers (3-G1 and 3-G2) with low generation dendrons is higher than those (3-G3) with high generation dendron. The somewhat lower isolation yield of the latter may be due to their higher solubilities in non-polar solvent used to remove excess dendron components. The structures of all compounds were confirmed by ${ }^{1} \mathrm{H}$ and ${ }^{13} \mathrm{C}$ NMR spectroscopy and they were exhibited very good correlation with the calculated molecular masses as evidenced by their FAB and/ or MALDI-TOF mass spectra. ${ }^{12}$

The symmetrical dendrimers 3-Gm contain two types of chromophoric units, namely 1,2-bispyridinium ethylene and 1,3-dialkoxybenzene. The ratios of these two types of units are $1: 2$ for 3-G1, $1: 6$ for 3-G2 and $1: 14$ for 3-G3. The absorption spectra of 3-G1 and 3-G3 in acetonitrile- 


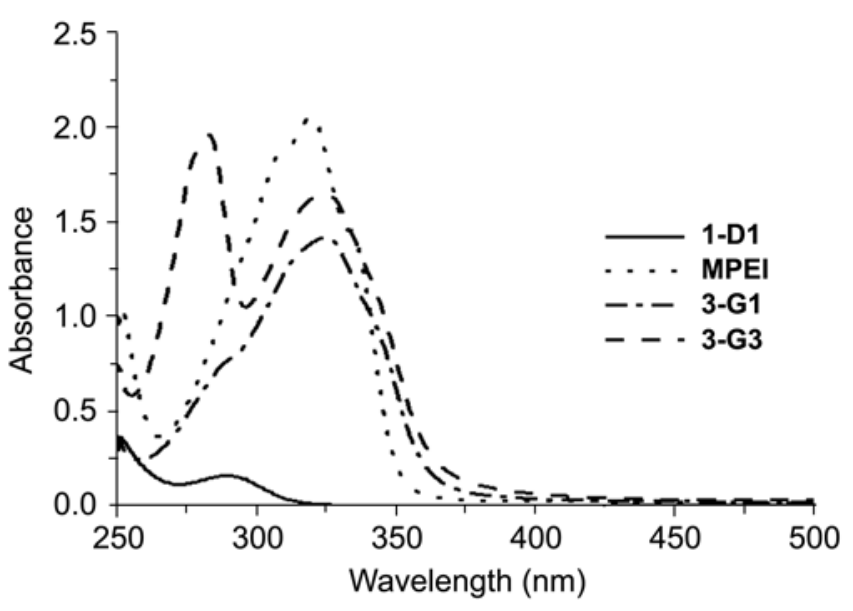

Figure 2. Absorption spectra of 3-G1, 3-G3, MPEI, and 1-D1 in DMSO-acetonitrile $(4: 1)$ solution at $298 \mathrm{~K}$.

dimethylsulfoxide $(3: 1)$ solution at $298 \mathrm{~K}$ is shown in Figure 2, where the spectra of its component units ( $N, N$ 'dimethyldipyridyliumylethylene diiodide (MPEI) and dendron 1-D1) are also displayed for comparison. The spectrum in 3-G1 is dominated by the strong absorption of dipyridyliumylethylene $\left(\lambda_{\max }=324 \mathrm{~nm}\right)$, with some contribution from the 1,3-dialkoxybenzene units around $283 \mathrm{~nm}$. The spectrum in 3-G3 is characterized by the strong absorption of dipyridyliumylethylene $\left(\lambda_{\max }=324 \mathrm{~nm}\right)$ with the strong absorption of the 1,3-dialkoxybenzene units around $283 \mathrm{~nm}$. These result is well-matched with the increasing number of 1,3-dialkoxybenzene units goes to higher generations. Therefore, as the dendrimer generation increases, the intensity of the absorption spectrum around $283 \mathrm{~nm}$ is raised because of the increasing number of 1,3-dialkoxybenzene units. But it is observed that a linear correlation of the molar absorption coefficient at $283 \mathrm{~nm}$ with the number of the 1,3dialkoxybenzene units is not fully satisfied. This result suggests that there are interactions between the 1,3-dialkoxybenzene units and dipyridyliumylethylene unit which may be assigned to charge-transfer (CT) transitions from the 1,3-dialkoxybenzene electron-donor units to dipyridyliumylethylene electron-acceptor core in dendrimers. ${ }^{4-6}$ This interaction could be confirmed by the fact that the dendrimers exhibit a broad and weak absorption tail at around $376 \mathrm{~nm}$ (Figure 2).

In summary, we have demonstrated the high yielding and first synthesis of dendrimers via the convergent method which contain the dipyridyliumylethylene unit as photoresponsible and redox-active unit at core. Further studies on the photochemical and electrochemical behaviors of core group in dendrimer are currently in progress.

Acknowledgement. This research was supported by University IT Research Center (ITRC) Project.

\section{References and Notes}

1. (a) Newkome, G. R.; Moorefield, C. N.; Vögtle, F. Dendrimers and Dendrons: Concepts, Synthesis, Applications; Wiley-VCH: Weinheim, 2001. (b) Fréchet, J. M. J.; Tomalia, D. A. Dendrimers and Other Dendritic Polymers; John Wiely \& Sons Ltd.: 2001.

2. (a) Fischer, M.; Vögtle, F. Angew. Chem. Int. Ed. 1999, 38, 885. (b) Bosman, A. W.; Janssen, H. M.; Meijer, E. W. Chem. Rev 1999, 99, 1665. (c) Hecht, S.; Fréchet, J. M. J. Angew. Chem. Int. Ed. 2001, 40, 74. (d) Grayson, S. M.; Fréchet, J. M. J. Chem. Rev. 2001, 101, 3819. (e) Jaung, J.-y. Bull. Korean Chem. Soc. 2004, 25,1453 .

3. Toba, R.; Quintela, J. M.; Peinador, C.; Román, E.; Kaifer, A. E. Chem. Commun. 2001, 857.

4. Ceroni, P.; Vicinelli, V.; Maestri, M.; Balzani, V.; Müller, W. M.; Müller, U.; Hahn, U.; Osswald, F.; Vögtle, F. New J. Chem. 2001, $25,989$.

5. Ghaddar, T. H.; Wishart, J. F.; Thompson, D. W.; Whitesell, J. K.; Fox, M. A. J. Am. Chem. Soc. 2002, 124, 8285.

6. Alvaro, M.; Ferrer, B.; García, H. Chem. Phys. Lett. 2002, 351, 374.

7. (a) Junge, D. M.; McGrath, D. V. Chem. Commun. 1997, 857. (b) Wang, S.; Advincula, R. C. Org. Lett. 2001, 3, 3831.

8. Mizutani, T.; Ikegami, M.; Nagahata, R.; Arai, T. Chem. Lett. 2001, 1014.

9. Hayakawa, J.; Momotake, A.; Arai, T. Chem. Commun. 2003, 94.

10. Oh, M.-K.; Bae, S.-E.; Yoon, J.-H.; Roberts, M. F.; Cha, E.; Lee, C.-W. J. Bull. Korean Chem. Soc. 2004, 25, 715.

11. Hawker, C. J.; Fréchet, J. M. J. J. Am. Chem. Soc. 1990, 112, 7638.

12. 3-G1: $98 \%$ yield; ${ }^{1} \mathrm{H}$ NMR $\left(500 \mathrm{MHz}, \mathrm{DMSO}^{-} \mathrm{d}_{6}\right) \delta 3.86$ (s, 12 H), $5.84(\mathrm{~s}, 4 \mathrm{H}), 6.66$ (s, $2 \mathrm{H}), 6.87(\mathrm{~s}, 4 \mathrm{H}), 8.27$ (s, $2 \mathrm{H}), 8.48$ (d, $J=10.3 \mathrm{~Hz}, 4 \mathrm{H}), 9.36(\mathrm{~d}, J=10.2 \mathrm{~Hz}, 4 \mathrm{H}) ;{ }^{13} \mathrm{C}$ NMR $(125 \mathrm{MHz}$, DMSO-d $\left._{6}\right) \delta 161.9,151.7,145.9,136.8,135.0,126.7,107.9$, 101.5, 63.8, 56.3; MS (FAB): m/z: 484.243 [M - 2Br- ].

13. 3-G2: $95 \%$ yield; ${ }^{1} \mathrm{H}$ NMR (500 MHz, DMSO-d $\left.{ }_{6}\right) \delta 3.82(\mathrm{~s}, 32$ $\mathrm{H}), 5.13(\mathrm{~s}, 8 \mathrm{H}), 5.82(\mathrm{~s}, 4 \mathrm{H}), 6.53(\mathrm{~m}, 4 \mathrm{H}), 6.65(\mathrm{~m}, 8 \mathrm{H}), 6.81$ (m, $2 \mathrm{H}), 6.91(\mathrm{~m}, 4 \mathrm{H}), 8.22(\mathrm{~s}, 2 \mathrm{H}), 8.44(\mathrm{~d}, J=11.3 \mathrm{~Hz}, 4 \mathrm{H})$, $9.28(\mathrm{~d}, J=11.1 \mathrm{~Hz}, 4 \mathrm{H}) ;{ }^{13} \mathrm{C}$ NMR $\left(125 \mathrm{MHz}, \mathrm{DMSO}-\mathrm{d}_{6}\right) \delta$ $161.4,160.7,151.6,145.9,139.8,136.9,135.0,126.6,108.9$, 106.4, 103.3, 100.2, 70.2, 63.8, 56.1; MS (FAB): m/z: 1028.014 $\left[\mathrm{M}-2 \mathrm{Br}^{-}\right]$.

14. 3-G3: $86 \%$ yield; ${ }^{1} \mathrm{H}$ NMR ( $500 \mathrm{MHz}, \mathrm{DMSO}^{\left.-\mathrm{d}_{6}\right)} \delta 3.81$ (s, 48 $\mathrm{H}), 5.11(\mathrm{~s}, 24 \mathrm{H}), 5.83(\mathrm{~s}, 4 \mathrm{H}), 6.52(\mathrm{~m}, 8 \mathrm{H}), 6.66(\mathrm{~m}, 16 \mathrm{H})$, 6.74 (br, $4 \mathrm{H}), 6.76$ (br, $8 \mathrm{H}), 6.83(\mathrm{br}, 2 \mathrm{H}), 6.95(\mathrm{~m}, 4 \mathrm{H}), 8.16$ (s, $2 \mathrm{H}), 8.40(\mathrm{~d}, J=9.9 \mathrm{~Hz}, 4 \mathrm{H}), 9.31(\mathrm{~d}, J=9.9 \mathrm{~Hz}, 4 \mathrm{H}) ;{ }^{13} \mathrm{C} \mathrm{NMR}$ $\left(125 \mathrm{MHz}, \mathrm{DMSO}_{\mathrm{d}}\right) \delta 161.4,160.8,160.3,151.6,145.9,140.1$, $139.8,136.9,134.9,126.6,108.9,107.5,106.2,103.2,102.0$, 100.2, 70.2, 70.0, 63.8, 56.0; MS (MALDI-TOF): m/z: 2117.381 $\left[\mathrm{M}-2 \mathrm{Br}^{-}\right]$. 